\section{MRC breach spurs reforms}

\section{London}

WiLHELM Feldberg, a former researcher at the Medical Research Council (MRC)'s National Institute for Medical Research (NIMR) in London, last year breached Britain's 1986 law governing animal experiments, an MRC-appointed independent inquiry has concluded. The MRC accepts the findings, and has already embarked on a series of reforms. But the Home Office, responsible for regulating British animal experiments, rejects the criticism that it 'jumped the gun', in allowing Feldberg to heat the abdomens of anaesthetized rabbits with a lamp bulb, before the MRC had decided to continue funding the work.

Last May, the Scottish animal rights group Advocates for Animals submitted video evidence to the Home Office, showing Feldberg carrying out surgical procedures at NIMR on rabbits which were apparently only lightly anaesthetized (see Nature 345, 190; 1990). Feldberg was hoping to understand clinical diabetes by studying the rise in blood sugar level after an animal's body surface is heated.

The inquiry, chaired by Sir Brian Bailey, chairman of a regional British television company and former MRC member, agreed that at least one rabbit suffered unnecessarily. Releasing the report last Monday, Bailey said that, after visiting NIMR and five other MRC research units, he was satisfied that the Feldberg case was an isolated incident, and not "the tip of the iceberg".

The report concludes that, apart from the failure properly to anaesthetize experimental animals, Feldberg broke the law in the summer of 1989 , when he continued with his heating experiments after NIMR's named veterinary surgeon had told him to stop. Feldberg's Home Office licence was amended to allow this procedure in September 1989, but the MRC decided not to fund the work in March 1990.

The report criticizes the MRC for deferring this decision, which was "generated by compassion" for a respected, but ageing, researcher, rather than by scientific judgement. The Home Office failed adequately to weigh the benefit of the research against the adverse effects to the experimental animals involved when they amended Feldberg's licence, the report says.

"We think the report has got it wrong", Home Office minister Angela Rumbold said on Monday, pointing out that two of the three referees who reviewed Feldberg's MRC grant proposal had seen some scientific value in the work.

Under the 1986 Act, animal experiments must be carried out in designated laboratories, at which one certificate

holder is responsible for ensuring that regulations are adhered to. NIMR director John Skehel, the certificate holder, is criticized in the report for giving Feldberg permission to work for a further five months after the MRC decided not to fund the project in March 1990. (In the event, the Home Office revoked the licences of Feldberg and his technician that May, once the allegations were made).

Although Skehel failed "technically" to prevent breaches of the law at NIMR, the report says that the fault lies more with the organization of NIMR, where hundreds of researchers are based; the heads of NIMR's 22 research divisions should be made personally responsible for ensuring UNIVERSITY OF CALIFORNIA

\section{San Francisco}

IN response to charges of inadequate management, University of California (UC) President David P. Gardner has unveiled a plan to strengthen the university's ties with the three US Department of Energy (DOE) laboratories it oversees.

The plan for stronger management proposes a 20-member President's Council

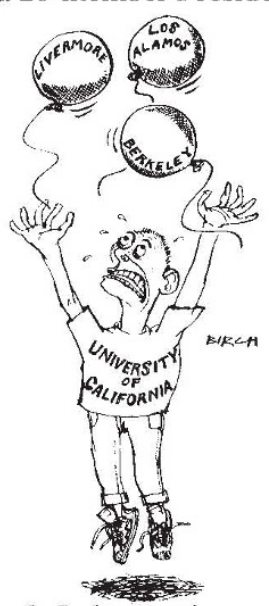

on National Laboratories and a major reorganization of Gardner's office, making two senior vice presidents responsible for oversight of laboratory operations. In recent years, critics have claimed that lax management has allowed environmental, security and drug-abuse problems to develop at the laboratories.

The proposal, presented to the UC Board of Regents this month, will also give UC faculty a greater role in monitoring the Lawrence Livermore National Laboratory, Lawrence Berkeley Laboratory and Los Alamos National Laboratory. Last year, the faculty on eight of the nine UC campuses voted to sever the 47-year relationships with the laboratories, arguing that it is fundamentally inappropriate for the university to be involved in the nuclear

\title{
Stronger management tactics for laboratories
}

that no future breaches occur, and NIMR's named veterinary surgeon should be given greater powers.

MRC secretary Dai Rees said that all the report's recommendations will be implemented - the MRC has already set up a Laboratory Animals Secretariat, to monitor and advise on animal experiments. But there will be no MRC disciplinary action: "We don't see any point in slapping wrists", Rees said.

Nevertheless, the Home Office may still pursue legal action. Its Animal Procedures Committee (APC) meets today (7 February) to consider the findings. The report also asks the Home Office to review each year the licences of researchers over 70 years of age (Feldberg was 89 when the breaches took place).

Peter Aldhous weapons research conducted at the Livermore and Los Alamos sites. But despite this opposition, the Board of Regents voted in September 1990 to renew five-year contracts with the DOE to manage the laboratories (see Nature 347, 322; 1990). Having lost that battle, the faculty has made no formal protest against the new proposal.

UC has tried to improve its relations with the laboratories in recent years, and last year appointed full-time on-site liaison officers at Livermore and Los Alamos, but the new plan is expected to add significantly to UC involvement. The proposed council would be composed of prominent business and government representatives as well as faculty members. It would be charged with reviewing UC management, monitoring the laboratories' operations and policies, assessing new research programmes and offering independent advice to the laboratories' directors.

UC senior vice presidents William $R$. Frazer and Ronald W. Brady will be assigned to review various research programmes, strategic planning and administrative and environmental policies.

Gardner expects the plan to be implemented as soon as DOE contract negotiations are completed, possibly as early as July. The current contracts, through which UC receives $\$ 12$ million a year to manage the 18,000 employees at the three sites, expire in September.

Laboratory officials, who are generally pleased to have access to the support and facilities offered by a closer relationship with UC, say that enhanced interactions make sense now as weapons research is scaled back. The new proposal may ensure a long-term role for the university as laboratories' scientific goals expand in areas such as alternative energy sources, global environmental changes and biomedical sciences. Elizabeth Schaefer 